\title{
ANTECEDENTES E CONSEQUENTES DA PROCRASTINAÇÃO DE DISCENTES EM DISCIPLINAS DO CURSO DE CIÊNCIAS CONTÁBEIS
}

\author{
Itzhak David Simão Kaveski 1 \\ Ilse Maria Beuren 2
}

- Artigo recebido em: 03/03/2019 -- Artigo aceito em: 27/02/2020 -- Segunda versão aceita em: 15/03/2020

\section{RESUMO}

Este estudo objetiva verificar os fatores que levam discentes do curso de Ciências Contábeis ao comportamento procrastinador em disciplinas da área e sua influência na vida acadêmica. Pesquisa descritiva foi realizada a partir de um levantamento, tendo como amostra 225 alunos de três universidades, uma particular, uma comunitária e uma pública. Para testar as hipóteses utilizou-se a modelagem de equações estruturais. Os resultados da pesquisa sinalizaram que os antecedentes pessoais e situacionais levam os discentes a procrastinarem as tarefas de disciplinas da área do curso. Constatou-se também que há relação positiva entre a procrastinação e o desvio de conduta acadêmica. Além disso, identificou-se que há relação negativa entre procrastinação e desempenho acadêmico. Conclui-se com base nos resultados que os fatores pessoais e situacionais levam à procrastinação de discentes do curso de Ciências Contábeis em disciplinas da área. Além disso, que o comportamento procrastinador pode afetar tanto o desempenho acadêmico como o desvio de conduta, inclusive colocar em risco as notas das disciplinas e a perda do curso. Os resultados do estudo contribuem para que docentes e discentes reflitam sobre os resultados negativos da procrastinação no decorrer das disciplinas e para a elaboração de planos e estratégias pedagógicas que possam melhorar a trajetória acadêmica dos alunos.

Palavras-Chave: Procrastinação. Desvio de Conduta. Desempenho Acadêmico.

\footnotetext{
1 Doutorando em Contabilidade pela Universidade Federal de Santa Catarina/UFSC. Professor da Universidade Federal de Mato Grosso do Sul/UFMS. Endereço: Campus Reitor João David Ferreira Lima, s/n, Bairro Trindade. Florianópolis/SC - CEP 88040-970 - Brasil. E-mail: itzhak.konoha@gmail.com. Telefone: (48) 3721-3891.

https://orcid.org/0000-0001-8691-9904

2 Doutora em Controladoria e Contabilidade pela Universidade de São Paulo/USP; Professora Titular da Universidade Federal de Santa Catarina/UFSC. Endereço: Campus Reitor João David Ferreira Lima, s/n, Bairro Trindade. Florianópolis/SC - CEP 88040-970 - Brasil. E-mail: ilse.beuren@gmail.com. Telefone: (48) 3721-3891.

https://orcid.org/0000-0003-4007-6408
} 


\title{
ANTECEDENTS AND CONSEQUENCES OF THE STUDENTES PROCRASTINATION IN DISCIPLINES OF THE ACCOUNTING SCIENCES COURSE
}

\begin{abstract}
This study aims to verify the factors that lead students of the Accounting Sciences course to procrastinating behavior in disciplines of the area and its influence in the academic life. Descriptive research was carried out through survey, having as a sample 225 students of three universities, one private, one communitarian and one public. To test the hypotheses, structural equation modeling was used. The results of the research indicated that the personal and situational antecedents lead students to procrastinate the tasks of the course's disciplines of the area. It was also found out that there is a positive relationship between procrastination and academic misconduct. In addition, it was identified that there is a negative relationship between procrastination and academic performance. Based on the results, it is concluded that the personal and situational factors lead students of the Accounting Sciences course to procrastination in disciplines of the area. In addition, procrastinating behavior can affect both academic performance and misconduct, including jeopardizing grades and failing the course. The results of the study contribute for teachers and students to reflect on the negative results of procrastination over the course of the disciplines and for the elaboration of pedagogical plans and strategies that can improve the students' academic trajectory.
\end{abstract}

Keywords: Procrastination. Misconduct. Academic Performance.

\section{INTRODUÇÃO}

A procrastinação representa um ato de atrasar desnecessariamente as tarefas ao ponto de experimentar um desconforto subjetivo (Milgram, Dangour \& Ravi, 1992). Pesquisas tem revelado que os traços de personalidade e situações em que 0 indivíduo se encontra podem ocasionar um comportamento procrastinador (Klingsieck, Grund, Schmid \& Fries, 2013), e que a procrastinação pode acarretar em consequências físicas, psicológicas e financeiras (Steel \& Klingsieck, 2016). Quando a procrastinação ocorre no domínio das experiências educacionais, é conhecida como procrastinação acadêmica (Milgram et al., 1992; Costa, 2007). Para os discentes, as atividades procrastinadas podem incluir qualquer forma de trabalho acadêmico, como tarefas a serem entregues em sala, agendamento de compromissos relacionados ao curso (por exemplo, reunião com o orientador), leitura do conteúdo para discussão em sala de aula ou preparação para os exames (Ferrari \& Scher, 2000; Costa, 2007).

O comportamento procrastinador é um fenômeno cada vez mais comum entre estudantes universitários (Costa, 2007; Klingsieck et al., 2013). A trajetória acadêmica exige certos compromissos, que por vezes são postergados pelos discentes, pois não conseguem conciliar com a vida pessoal (Amaro, Semprebon, Baron Junior \& Dezevecki, 2016). Assim, algumas pesquisas têm buscado identificar os antecedentes da procrastinação acadêmica (Milgram et al., 1992; Ferrari \& Scher, 2000; Dewitte \& Schouwenburg, 2002; Klingsieck et al., 2013). Esses 
estudos destacam como antecedentes os motivos pessoais (motivacionais, volitivos, emocionais, competência e personalidade) e situacionais (sociais, estrutura externa e tarefas inerentes). Também o uso de mídias sociais, tais como facebook, twitter e instagram, tornou-se um vício entre os estudantes de graduação, o que tem impulsionado a procrastinação e, por consequência, o não cumprimento das atividades acadêmicas (Medeiros, Antonelli \& Portuhak, 2019).

Um aspecto que tem recebido atenção em estudos de procrastinação acadêmica é a sua influência na vida universitária dos discentes. O desempenho acadêmico tem sido o principal foco desses estudos, pois um alto desempenho depende do cumprimento de prazos na entrega das tarefas das disciplinas e boas notas nos exames (Ribeiro, Avelino, Colauto \& Casa Nova, 2014; Kim \& Seo, 2015; Amaro et al., 2016; Grunschel, Schwinger, Steinmayr \& Fries, 2016; Raash \& Silveira-Martins, 2016; Silva, Silva, Vilela \& Oliveira, 2016; Semprebon, Amaro \& Beuren, 2017). A procrastinação de tarefas acadêmicas impacta no desempenho dos discentes e pode afetar toda a vida educacional e profissional (Raash \& Silveira-Martins, 2016).

Outro aspecto que tem sido tema de interesse de diversos pesquisadores da área de ensino (Carpenter, Harding, Finelli, Montgomery \& Passow, 2006; Klein, Levenburg, McKendall \& Mothersell, 2007; Simkin \& Mcleod, 2010; Patrzek, Sattler, Venn, Grunschel \& Fries, 2014) é o desvio de conduta. O desvio de conduta em ambientes educacionais é um termo usado para cobrir uma ampla gama de más condutas acadêmicas por parte dos discentes, por exemplo, plágio, cola na prova, copiar a lição de casa dos colegas, entre outros (Carpenter et al., 2006; Patrzek et al., 2014).

De acordo com Carpenter et al. (2006), o desvio de conduta interfere na integridade do processo de aprendizagem, no comportamento a longo prazo do discente e na capacidade das instituições acadêmicas para alcançar seus objetivos declarados, ou seja, o aprendizado. Assim, Patrzek et al. (2014) verificaram que os discentes que apresentam um comportamento procrastinador, são mais propensos a cometer desvios de condutas acadêmicas. Entretanto, os autores afirmam que a relevância da procrastinação acadêmica na compreensão do desvio de conduta deve ser confirmada com mais estudos.

Com base no exposto, a questão de pesquisa que orienta este estudo é a seguinte: Quais os antecedentes e consequentes da procrastinação de discentes em disciplinas do curso de Ciências Contábeis? Os discentes do curso de Ciências Contábeis costumam trabalhar já nos primeiros semestres do curso, o que esperase que Ihes exija maior disciplina nos estudos e lhes ensine a relevância do cumprimento dos prazos inerentes ao ofício do profissional da área contábil, ao mesmo tempo que na survey investigaram-se alunos de três perfis de universidade: i) particular; ii) comunitária (instituição sem fins lucrativos, mantida por uma Fundação); e iii) pública. O objetivo do estudo é verificar os fatores que levam discentes do curso de Ciências Contábeis ao comportamento procrastinador em disciplinas da área e sua influência no desvio de conduta e desempenho acadêmico.

Com esta pesquisa busca-se ampliar a literatura a respeito da procrastinação acadêmica de discentes do curso de Ciências Contábeis, atentando-se aos antecedentes e a sua influência no desempenho acadêmico 
e no desvio de conduta. Justifica-se pela relevância de se ter uma melhor compreensão do amplo fenômeno da procrastinação acadêmica e suas consequências para os discentes (Costa, 2007; Raash \& Silveira-Martins, 2016). Também pela importância de conhecer os antecedentes pessoais e situacionais subjacentes à presença da procrastinação, pois podem ser prevenidas e intervindas (Klingsieck et al., 2013). Destaca-se ainda que não foram encontrados estudos no Brasil a respeito da relação entre procrastinação acadêmica e desvio de conduta (Patrzek et al., 2014). Além disso, contribui para que os gestores educacionais criem mecanismos administrativos e os docentes desenvolvam mecanismos de aprendizagem que ajudem a minimizar o comportamento procrastinador (Amaro et al., 2016; Semprebon et al., 2017; Medeiros et al., 2019).

\section{REVISÃO DA LITERATURA}

\subsection{Relação entre os Antecedentes da Procrastinação e Procrastinação Acadêmica}

A procrastinação acadêmica pode ser definida como o atraso intencional de tarefas acadêmicas que devem ser completadas dentro de um prazo específico de tempo, apesar de a expectativa do atraso ser algo desagradável (Costa, 2007; Steel \& Klingsieck, 2016). Portanto, o ato de procrastinar pode afetar toda a vida acadêmica de um estudante universitário, seja em nível de graduação ou pós-graduação, colocando em risco as notas das disciplinas e os trabalhos de conclusão, o que pode acarretar na perda do curso (Costa, 2007; Ribeiro et al., 2014; Kim \& Seo, 2015; Semprebon et al., 2017).

De acordo com Chu e Choi (2005), existem dois tipos de procrastinadores, os ativos e os passivos. Os passivos são os tradicionais procrastinadores, ou seja, são aqueles que não sabem planejar seu tempo para realização das atividades, sofrem por não conseguirem terminar as tarefas dentro do prazo estipulado, o que pode prejudicar a vida acadêmica, por exemplo. Quando o prazo aperta, os procrastinadores passivos se sentem pressionados e tornam-se pessimistas em suas perspectivas, especialmente sobre a capacidade de alcançar resultados satisfatórios. Os pensamentos de insegurança e inadequação aumentam as chances de fracasso e induzem ao sentimento de culpa e depressão.

Já os procrastinadores ativos são aqueles que adiam as atividades que consideram menos importantes, para realizar aquelas consideradas mais importantes, sem interferir na qualidade das mesmas, o que pode acabar não prejudicando a vida acadêmica. Quando confrontados com tarefas de última hora, os procrastinadores ativos se sentem desafiados e motivados, consequentemente, são capazes de completa-las, enquanto os procrastinadores passivos são mais propensos a desistirem (Chu \& Choi, 2005).

Em ambientes acadêmicos, a procrastinação pode afetar negativamente a aprendizagem, a realização de atividades e a qualidade de vida (Raasch \& Silveira-Martins, 2016). Assim, autores tem buscado identificar os fatores que levam os acadêmicos a procrastinarem suas atividades e dois motivos têm se destacado, pessoais e situacionais (Milgram et al., 1992; Ferrari \& Scher, 2000; Dewitte \& Schouwenburg, 2002). Segundo Klingsieck et al. (2013) e Steel e Klingsieck (2016), os motivos pessoais referem-se aos aspectos associados com 
atributos pessoais dos discentes (fatores motivacionais, volitivos, emocionais, competência e personalidade), enquanto os situacionais incorporam os aspectos relacionados a situações do cotidiano (fatores sociais, estrutura externa e tarefas inerentes).

Milgram et al. (1992) investigaram através de um experimento, 112 estudantes do sexo feminino de um colégio israelita e identificaram três motivos pessoais, autocontrole, ansiedade e agressividade passiva. Quanto aos motivos situacionais, consideraram três variáveis moderadoras: tempo para finalização da atividade, rigor quanto ao início da atividade e plausibilidade (tipo de explicação dada às estudantes sobre a finalidade da pesquisa). Os resultados mostraram apenas a variável autocontrole significativamente correlacionada com a procrastinação, em que as estudantes com baixo autocontrole procrastinaram mais as atividades do que as demais. Quanto à moderação, foi constatado que - grupo de alunas que recebeu explicação plausível sobre a finalidade da pesquisa procrastinou significativamente menos na conclusão das atividades do que o grupo que recebeu explicações implausíveis. Nota-se que tanto os motivos pessoais como os situacionais levaram as acadêmicas a procrastinarem.

Ferrari e Scher (2000) investigaram por cinco dias consecutivos 37 estudantes (30 mulheres e 7 homens) universitários. Foi solicitado que listassem as tarefas diárias acadêmicas e não acadêmicas que pretendiam completar e que registrassem se realmente as tarefas foram completadas dentro do prazo. Os autores identificaram que os estudantes eram mais propensos a procrastinar em tarefas que consideravam muito difíceis, mas aquelas consideradas desagradáveis o número de procrastinações foi maior, tanto para as acadêmicas como as não acadêmicas. Assim, os autores concluíram que as tarefas acadêmicas e não acadêmicas podem ser desafiadoras, mas devem ser agradáveis, o que pode aumentar a probabilidade de serem completadas pelos alunos.

Dewitte e Schouwenburg (2002) realizaram dois estudos para investigar os fatores pessoais que levam acadêmicos a procrastinarem seus estudos. No primeiro estudo, 147 calouros responderam cinco fatores de personalidades (instabilidade emocional, extroversão, amabilidade, conscienciosidade e abertura para a experiência) e posteriormente foram relacionados com o nível de procrastinação. Destes cinco fatores, a amabilidade foi retirada da relação por não apresentar adequação nos dados quanto aos pressupostos da análise fatorial. Os achados revelaram que a procrastinação estava intimamente relacionada com a falta de perseverança, isto é, a incapacidade de completar as atividades. No segundo estudo, os mesmos calouros foram acompanhados durante 11 semanas quanto ao preparo para os exames. Os calouros forneceram as intenções que os levaram a se preparar para os exames e as razões pelas quais eles não conseguiram se preparar e o impacto percebido na nota final. Assim, os autores concluíram que os acadêmicos procrastinadores são aqueles altamente motivados em estudar para o exame, mas que não possuem a capacidade de afastar as tentações e distrações durante suas atividades de estudo.

$\mathrm{H}_{1}$ : Há relação significativa entre os motivos pessoais e situacionais e a procrastinação.

A não rejeição da hipótese $H_{1}$ indicará que os motivos pessoais e situacionais dos discentes do curso de Ciências Contábeis podem explicar a 
Determinantes e Consequentes da Procrastinação de Discentes em Disciplinas do Curso de Ciências Contábeis

procrastinação das atividades acadêmicas. Dessa forma, será possível identificar quais motivos pessoais e situacionais podem aumentar ou diminuir a procrastinação das atividades acadêmicas relacionadas a área contábil.

\subsection{Relação entre Procrastinação Acadêmica e Desvio de Conduta}

O desvio de conduta acadêmica dos estudantes tem chamado a atenção de profissionais e instituições de ensino superior (Carpenter et al., 2006; Simkin \& Mcleod, 2010; Patrzek et al., 2014). A preocupação quanto a este fenômeno deve-se ao fato de que é uma transgressão contra a integridade acadêmica que implica tomar uma vantagem injusta, resultando em uma falsa representação da capacidade de um discente quanto à compreensão de diversas áreas do conhecimento (Klein et al., 2007).

Para Carpenter et al. (2006), o desvio de conduta acadêmica tornou-se um problema sério em instituições de ensino superior. Dessa forma, os autores investigaram a percepção de 643 estudantes de engenharia quanto a desonestidade acadêmica de onze instituições de ensino superior dos Estados Unidos. Segundo os autores, os alunos de engenharia estavam dispostos a se envolver em comportamentos que eles definiram como errado e que poderiam ocasionar riscos de punição. No geral, os autores elucidam que a responsabilidade pela promoção da integridade educacional encontra-se com toda a comunidade acadêmica, incluindo estudantes, professores e a própria instituição de ensino.

De acordo com Klein et al. (2007), os discentes da área de negócios são considerados os principais acadêmicos a terem uma má conduta, e que este fenômeno pode ser um fator que contribui para os escândalos de fraudes que afligiram e afligem as empresas. No entanto, ao analisarem 124 estudantes da área de negócios e 144 estudantes de outras áreas (Biomedicina, Direito, Engenharia, Enfermagem e nas áreas de Ciências Sociais) da Western Washington University, constataram que os discentes da área de negócios não trapaceiam mais ou menos que estudantes de outras áreas. Segundo os autores, as atitudes dos alunos da área de negócios, sobre o que constitui desvio de conduta, inclusive são menores do que as de estudantes das demais áreas.

Simkin e McLeod (2010) investigaram os antecedentes do desvio de conduta acadêmica de 87 discentes da área de negócios e 57 discentes de outras áreas. Conforme os autores, a motivação de antecipar-se frente aos demais colegas e as determinações morais explicam as atitudes de desvio de conduta, que consequentemente aumenta a intenção de fraude. Ainda foi possível identificar que a família (pais, irmãos e outros membros da família) provavelmente influencia a intenção dos discentes a cometerem desvios de conduta acadêmica.

Visto a crescente preocupação quanto ao comportamento desviante pelos discentes universitários, Patrzek et al. (2014) investigaram se a procrastinação acadêmica influencia no desvio de conduta entre 1.359 e 2.207 discentes de diferentes disciplinas acadêmicas em quatro universidades alemãs. Os achados demonstraram que o comportamento procrastinador dos discentes afeta de forma positiva a má conduta acadêmica. Os autores concluíram que os resultados desta relação podem ser usados para informar as administrações 
universitárias, conselheiros, professores e estudantes sobre os riscos da procrastinação acadêmica.

Diante do exposto, em que é abordado o desvio de conduta como uma consequência da procrastinação acadêmica, enuncia-se a segunda hipótese da pesquisa:

$\mathrm{H}_{2}$ : Há relação positiva entre a procrastinação e o desvio de conduta acadêmica.

A não rejeição da hipótese $\mathrm{H}_{2}$ indicará que os discentes do curso de Ciências Contábeis que procrastinam as atividades relativas as disciplinas da área contábil tendem a apresentar uma má conduta acadêmica em comparação a aqueles que não apresentam um comportamento procrastinador. Dessa forma, é esperado que a procrastinação dos discentes aumente o desvio de conduta.

\subsection{Relação entre Procrastinação Acadêmica e Desempenho Acadêmico}

A premissa de que estudantes procrastinadores possuem menor desempenho acadêmico foi analisado por estudos que usaram medidas de desempenho auto-relatado (Kim \& Seo, 2015; Amaro et al., 2016; Grunschel et al., 2016; Raash \& Silveira-Martins, 2016; Semprebon et al., 2017) e de forma externa (Ribeiro et al., 2014; Kim \& Seo, 2015; Silva et al., 2016). De acordo com Grunschel et al. (2016), não é de surpreender que os alunos que procrastinam tenham um baixo desempenho acadêmico, visto que são mais propensos a atrasar nas tarefas e se preparar na última hora para os exames.

Ribeiro et al. (2014) investigaram a correlação entre o comportamento procrastinador e o desempenho acadêmico de alunos do curso de graduação em Ciências Contábeis. A amostra da pesquisa foi composta por 200 estudantes de três instituições de ensino públicas brasileiras (UFMG, UFPR e UNICENTRO). Os autores também verificaram se $O$ gênero estaria correlacionado ao comportamento procrastinador. Os resultados da matriz de correlação indicaram associação negativa e significativa entre o comportamento procrastinador e o desempenho acadêmico dos alunos. Quanto ao gênero, não foram encontradas evidências de que a procrastinação tenha diferenças relacionadas ao gênero masculino e feminino. Assim, concluíram que os estudantes, ao postergar a execução de suas tarefas, possuem desempenho inferior do que aqueles que realizam suas atividades em dia.

Por meio de uma meta-análise, Kim e Seo (2015) investigaram a conclusão de 33 estudos que analisaram a relação entre procrastinação e desempenho acadêmico. A meta-análise revelou que o comportamento procrastinador está negativamente relacionado com o desempenho acadêmico. De acordo com os autores, a relação negativa existe apenas quando o desempenho é avaliado de forma externa, enquanto que não foi observada relação significativa entre o desempenho auto-relatado e a procrastinação. Isso sugere que o desempenho avaliado externamente tende a ser menor do que o desempenho auto-relatado.

Grunschel et al. (2016) realizaram dois estudos para examinar se o uso de estratégias de regulação motivacional (ações ou táticas, em relação às quais os indivíduos podem controlar conscientemente seus afetos e emoções para iniciar, manter ou complementar sua disposição ao concluir uma atividade de 
aprendizagem) tem efeito na procrastinação acadêmica, no desempenho acadêmico dos alunos e no bem-estar. No primeiro, investigaram 419 estudantes de graduação da área de humanas em uma universidade alemã. No segundo, investigaram 219 estudantes alemãs de graduação de diversas áreas, como educação e psicologia. Os resultados de ambos os estudos mostraram que as estratégias de regulação motivacional afetam de forma positiva o desempenho acadêmico dos alunos e o bem-estar, mediado pela procrastinação acadêmica. Assim, alunos que utilizam estratégias de regulação motivacional procrastinam menos e, consequentemente, apresentam um desempenho acadêmico melhor e são mais satisfeitos academicamente e com a vida pessoal.

Raash e Silveira-Martins (2016) avaliaram a relação da procrastinação com o desempenho acadêmico de graduandos em cursos da área de administração. O resultado foi baseado em dados de 149 acadêmicos de uma Instituição Federal de Ensino Superior. Os resultados indicaram relação positiva entre a procrastinação e o desempenho acadêmico, ou seja, mesmo os alunos procrastinando apresentaram um bom desempenho em comparação aqueles que não procrastinam. Para os autores, a relação positiva ocorreu, pois, os alunos são procrastinadores ativos e conseguem fazer as atividades de forma estratégica, dentro do limite temporal de execução e ainda respeitam os prazos e requisitos estabelecidos pelos professores. Finalmente, muitos acadêmicos procrastinam por terem prazos simultâneos para cumprir, além das atividades acadêmicas possuem obrigações do cotidiano, como filhos e trabalho.

Silva et al. (2016) investigaram se os diferentes períodos cursados ou em curso dos graduandos em Ciências Contábeis influenciam na procrastinação das atividades acadêmicas, e a associação da procrastinação às variáveis gênero e desempenho acadêmico. Pesquisaram uma amostra de 100 alunos da Faculdade de Ciências Integradas do Pontal, na Universidade Federal de Uberlândia (UFU). Os resultados indicaram que os estudantes dos períodos finais do curso estão mais associados a um comportamento procrastinador. Quanto a associação do gênero do estudante com o comportamento procrastinador, verificou-se que os discentes do gênero masculino tendem a procrastinar mais. Finalmente, constataram que os acadêmicos que apresentam um comportamento procrastinador estão associados a um baixo coeficiente de rendimento acadêmico, disponibilizado pela instituição investigada.

Amaro et al. (2016) verificaram a influência da procrastinação acadêmica na autoavaliação de desempenho de acordo com os níveis de percepção de autoeficácia dos discentes. Foi aplicado um questionário a 469 discentes dos cursos de Ciências Contábeis, Administração, Ciências Econômicas, Marketing e Turismo de uma instituição de ensino superior privada, situada na cidade de Curitiba/PR. Os resultados indicaram que a procrastinação acadêmica exerce influência negativa na autoavaliação de desempenho dos discentes. Outrossim, por meio da moderação, o grupo de estudantes com baixa autoeficácia foi o que apresentou resultados significativos quanto a influência do comportamento procrastinador no desempenho acadêmico.

Semprebon et al. (2017) verificaram a influência da procrastinação no desempenho acadêmico de discentes de Ensino Superior, considerando como variável moderadora o senso de poder. A amostra foi composta por 469 alunos dos cursos de Ciências Contábeis, Ciências Econômicas, Administração, Marketing e Turismo, matriculados em uma instituição de Ensino Superior privada. 
Os autores concluíram que existe influência negativa e significativa da procrastinação no desempenho dos discentes e que esta relação só pode ser confirmada nos estudantes com baixo senso de poder.

Assim, verifica-se que a maioria dos estudos encontrou relação negativa entre o comportamento procrastinador e o desempenho acadêmico, e que apenas um estudo encontrou relação positiva, mas que os respondentes podem ser considerados procrastinadores ativos. Com base nos argumentos expostos e nos resultados das pesquisas teórico-empíricas apontadas, formulou-se a terceira hipótese da pesquisa:

$\mathrm{H}_{3}$ : Há uma relação negativa entre a procrastinação e o desempenho acadêmico.

A não rejeição da hipótese $\mathrm{H}_{3}$ indicará que os discentes do curso de Ciências Contábeis que procrastinam as atividades relativas as disciplinas da área, tendem a apresentar desempenho acadêmico menor em comparação a aqueles que não apresentam comportamento procrastinador. Dessa forma, é esperado que a procrastinação dos discentes diminua o desempenho acadêmico. Na Figura 1, apresenta-se o modelo relacional da pesquisa, que exibe as hipóteses acima contextualizadas e que norteiam este estudo.

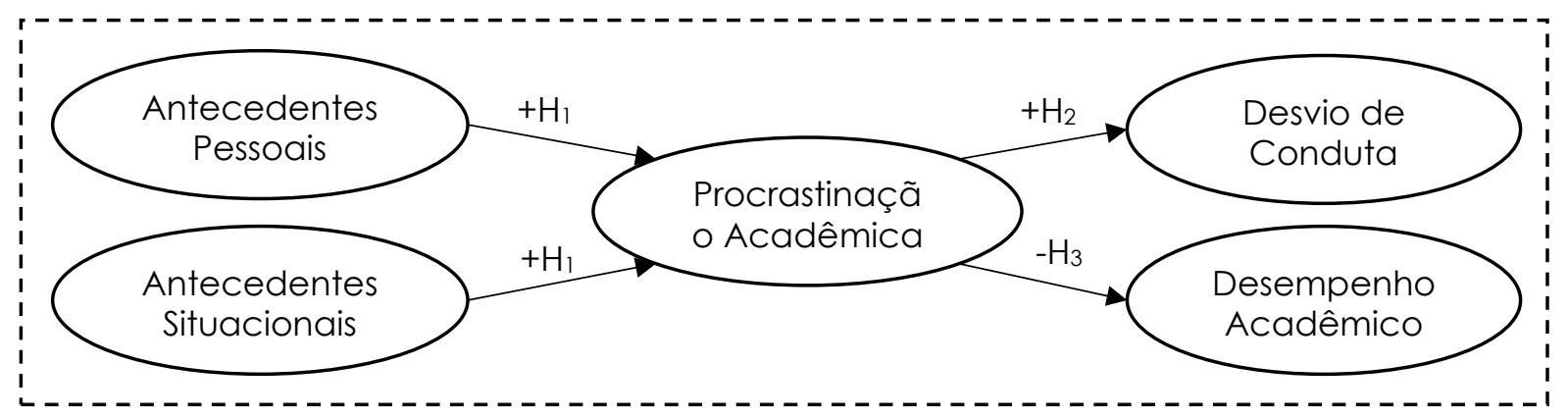

Figura 1 - Modelo relacional da pesquisa Fonte: Elaborada pelos autores.

Em conformidade com as hipóteses e com o modelo teórico da pesquisa, conjectura-se que os antecedentes pessoais e situacionais são os fatores que levam à procrastinação acadêmica de discentes do curso de Ciências Contábeis. E, que o comportamento procrastinador influencia positivamente no desvio de conduta por parte do discente e diminui seu desempenho acadêmico em disciplinas da área contábil.

\section{PROCEDIMENTOS METODOLÓGICOS}

Esta pesquisa de levantamento ou survey foi realizada com aplicação de um questionário, que foi respondido por 225 estudantes de três universidades da região Sul do Brasil, dos segmentos privada, comunitária e pública. O intuito de considerar na pesquisa discentes de três segmentos de instituições de ensino superior decorre da suspeita de que não necessariamente uma delas seja representativa das outras no comportamento procrastinador em disciplinas do curso de Ciências Contábeis. 
O número mínimo de respondentes para aplicação do estudo foi calculado por meio do software G*Power, o que implica "avaliar o constructo ou variável latente que recebe o maior número de setas ou tem o maior número de preditores" (Ringle, Silva \& Bido, 2014, p. 58). Duas variáveis (motivos pessoais e situacionais) foram utilizadas como fatores antecedentes da procrastinação acadêmica, em que a procrastinação está relacionada com o desvio de conduta e o desempenho acadêmico. O tamanho do efeito utilizado foi de 0,15 , o nível de significância de a foi de 0,05, o poder da amostra de 1- $\beta$ foi de 0,8, com base em Ringle et al. (2014), e o número de preditores foi quatro. Assim, a amostra mínima exigida para o modelo foi de 85 respondentes.

\subsection{Construtos e Instrumento da Pesquisa}

Na Figura 2, apresentam-se os construtos da pesquisa, as respectivas assertivas e as referências que embasaram ambos.

Observa-se que, para cada construto, foram formuladas assertivas, em relação às quais se solicitou aos discentes que indicassem o seu grau de concordância com cada frase em uma escala de seis pontos, de 1 (muito raramente) a 6 (muito frequentemente). Algumas assertivas foram retiradas de estudos internacionais (Klingsieck et al., 2013; Patrzek et al., 2014), assim foi realizada a tradução para a língua portuguesa, posteriormente as assertivas foram novamente convertidas para a língua inglesa, a fim de certificar-se sobre a correta tradução das mesmas.

O instrumento foi submetido a um pré-teste, antes de ser utilizado para a coleta dos dados, por um professor doutor em Ciências Contábeis da universidade pública e participa de curso de pós-graduação stricto sensu da área e por dois mestres em contabilidade, um que leciona na instituição privada e outro na instituição comunitária. Após a leitura das questões pelos docentes, foi possível a detecção de assertivas do questionário que não estavam com redação inteligível, assim alterações foram realizadas para a versão final. 


\begin{tabular}{|c|c|}
\hline Construtos & Assertivas \\
\hline \multirow{13}{*}{$\begin{array}{l}\text { Antecedentes } \\
\text { pessoais } \\
\text { (Klingsieck et al., } \\
\text { 2013) }\end{array}$} & 1.Procrastino porque não estou intrinsecamente motivado, por exemplo, pela falta de interesse na atividade. \\
\hline & $\begin{array}{l}\text { 2.Defino o meu prazo pessoal para bem antes do prazo oficial de entrega da tarefa. Dessa forma, eu posso adiar a } \\
\text { tarefa e, ainda assim, terminar a tempo. }\end{array}$ \\
\hline & 3.Atraso tarefas e decisões porque acredito que trabalho melhor sob pressão. \\
\hline & 4.Não sou capaz de sentar e iniciar uma tarefa, por mais que eu queira. \\
\hline & 5.Me distraio com facilidade quando inicio uma tarefa. \\
\hline & 6.Tenho dificuldades para organizar minhas tarefas ou cumprir minha agenda pessoal no prazo. \\
\hline & 7.Tenho medo de possíveis consequências negativas devido à falha de não realizar as tarefas. \\
\hline & 8.Tenho medo de me sentir desapontado por causa da falha de não realizar as tarefas. \\
\hline & 9.Subestimo o tempo necessário para cumprir a tarefa; consequentemente, começo a tarefa tarde demais. \\
\hline & 10.Procrastino na tarefa quando não sei o que fazer ou como fazer e não procuro ajuda. \\
\hline & $\begin{array}{l}\text { 11.Atribuo a procrastinação ao meu estilo de vida espontâneo, o qual é refletido, de certa forma, por um tipo de } \\
\text { atitude despreocupada. }\end{array}$ \\
\hline & $\begin{array}{l}\text { 12.Não sou capaz de tomar uma decisão sem extensivamente - ou mesmo obsessivamente - pesar todas as vantagens } \\
\text { e desvantagens. }\end{array}$ \\
\hline & $\begin{array}{l}\text { 13.Além dos aspectos preferencialmente orientados ao processo, os antecedentes pessoais também incluem a } \\
\text { categoria de antecedentes das características preferidas, compostos de espontaneidade, problemas com tomar } \\
\text { decisões e preguiça. }\end{array}$ \\
\hline \multirow{12}{*}{$\begin{array}{l}\text { Antecedentes } \\
\text { situacionais } \\
\text { (Klingsieck et al., } \\
\text { 2013) }\end{array}$} & $\begin{array}{l}\text { 1.Não procrastino em atividades que envolvem interdependência (por exemplo, com outros alunos ou outras } \\
\text { disciplinas). }\end{array}$ \\
\hline & $\begin{array}{l}\text { 2.O tema "outras significantes atitudes em torno da procrastinação" compreende as atitudes dos pares, que tendem } \\
\text { a ser, em sua maioria, indiferentes ou positivas (por exemplo, alguns ficam, de certa forma, impressionados, do tipo: } \\
\text { "Uau! Não acredito! Você deu conta disso!"). }\end{array}$ \\
\hline & $\begin{array}{l}\text { 3.Estereótipos podem ser buscados na família ou entre amigos (por exemplo, porque minhas irmãs são muito parecidas } \\
\text { comigo quando se trata de procrastinação). }\end{array}$ \\
\hline & 4.Procrastinei em alguma atividade porque eu tinha que fazer outra coisa mais importante ou ir a algum compromisso. \\
\hline & 5.Tentações sociais são as mais frequentes distrações que fazem adiar tarefas. \\
\hline & 6.Tenho liberdade para organizar o ciclo de estudos ao longo dos anos. \\
\hline & 7.A procrastinação é mais acentuada para as tarefas mais exigentes. * $(R)$ \\
\hline & 8.A procrastinação é mais acentuada para as tarefas mais compreensíveis. \\
\hline & 9.A procrastinação é mais acentuada para as tarefas menos atraentes. \\
\hline & 10.A procrastinação é mais acentuada para tarefas com falta de incentivos. \\
\hline & 11.Primeiro, procrastinei porque a tarefa não era importante. ${ }^{*}(\mathrm{R})$ \\
\hline & 12.Segundo, procrastinei porque a tarefa era extremamente importante. \\
\hline
\end{tabular}




\begin{tabular}{|c|c|}
\hline Construtos & Assertivas \\
\hline \multirow{10}{*}{$\begin{array}{c}\text { Procrastinação } \\
\text { acadêmica } \\
\text { (Costa, 2007) }\end{array}$} & 1.Quando o professor manda fazer uma tarefa na aula começo a fazê-la imediatamente. * $(\mathrm{R})$ \\
\hline & $\begin{array}{l}\text { 2. Quando não compreendo um assunto ou exercício da aula tento esclarecer a dúvida o mais rapidamente possível. } \\
*(R)\end{array}$ \\
\hline & 3.Estou a par das matérias porque estudo todos os dias. *(R) \\
\hline & 4.Cumpro o meu plano de estudo. ${ }^{*}(\mathrm{R})$ \\
\hline & 5.Me falta concentração quando estudo para as provas. *(R) \\
\hline & 6.Perco-me em tantas coisas/atividades que não me sobra tempo para estudar para as provas. \\
\hline & $\begin{array}{l}\text { 7.Interrompo o tempo de estudo para as provas para fazer outras coisas (ex., assistir TV, jogar no computador, navegar } \\
\text { nas redes sociais no celular, etc.). }\end{array}$ \\
\hline & 8.No estudo para os testes adio para o dia seguinte o que deveria ter feito hoje. \\
\hline & 9.Quando um trabalho é muito difícil desisto e passo para outra tarefa. \\
\hline & 10.Quando tenho que fazer um trabalho para avaliação na disciplina começo o mais cedo possível. *(R) \\
\hline \multirow{2}{*}{$\begin{array}{c}\text { Procrastinação } \\
\text { acadêmica } \\
\text { (Elaboração Própria) }\end{array}$} & 11.Quando o professor manda fazer uma leitura em casa, procuro fazê-la imediatamente. *(R) \\
\hline & 12.Interrompo as leituras que o professor solicitou para fazer outras atividades mais agradáveis e divertidas. \\
\hline \multirow{9}{*}{$\begin{array}{l}\text { Desvio de conduta } \\
\text { (Patrzek et al., 2014) }\end{array}$} & 1.Uso uma falsa desculpa ou abuso de um atestado médico para adiar uma prova ou um prazo. \\
\hline & 2.Copio da prova de um colega no momento da avaliação. \\
\hline & 3.Uso meios proibidos, como anotações (cola), nas provas. \\
\hline & 4. Levo anotações (cola) ou outros meios proibidos nas provas. \\
\hline & 5.Conscientemente uso pensamentos ou citações de autores sem o devido destaque de autoria (plágio). \\
\hline & 6.Copio partes de protocolos/dever de casa de colegas \\
\hline & 7.Produzo ou falsifico dados/resultados/fatos \\
\hline & $\begin{array}{l}\text { 8. Costumo ter más condutas acadêmicas (navegação nas redes sociais durante as aulas, envio de mensagens para } \\
\text { colegas). }\end{array}$ \\
\hline & $\begin{array}{l}\text { 9. Costumo ter várias outras más condutas acadêmicas (colegas, conversas paralelas durante as aulas expositivas do } \\
\text { professor, etc.). }\end{array}$ \\
\hline \multirow{2}{*}{$\begin{array}{c}\text { Desvio de conduta } \\
\text { (Elaboração } \\
\text { própria) }\end{array}$} & 10.Invento uma desculpa para justificar a falta de leitura do material que o professor indicou como tarefa de casa. \\
\hline & $\begin{array}{l}\text { 11.Costumo me esquivar das leituras previamente estabelecidas pelo professor para o acompanhamento do } \\
\text { conteúdo da aula seguinte. }\end{array}$ \\
\hline \multirow{2}{*}{$\begin{array}{l}\text { Desempenho } \\
\text { acadêmico } \\
\text { (Elaboração } \\
\text { própria) }\end{array}$} & 1.No geral, estou satisfeito com o meu desempenho acadêmico em comparação com minha dedicação aos estudos. \\
\hline & $\begin{array}{l}\text { 2.No geral, estou satisfeito com o meu desempenho acadêmico em comparação com a dedicação aos estudos dos } \\
\text { meus colegas e o seu desempenho. }\end{array}$ \\
\hline
\end{tabular}

Nota: ${ }^{*}(\mathrm{R})$ questão reversa.

Figura 2 - Construto da pesquisa. 


\subsection{Procedimentos de Análise dos Dados}

Para a análise dos dados, inicialmente fez-se a caracterização dos respondentes e calcularam-se as estatísticas descritivas. Posteriormente, para testar as hipóteses, utilizou-se a Modelagem de Equações Estruturais (Structural Equation Modeling - SEM), por meio de Mínimos Quadrados Parciais (Partial Least Square - PLS), valendo-se do software estatístico SmartPLS. O PLS-SEM é uma técnica estatística que permite aos pesquisadores estimar modelos complexos de caminhos, para verificar as relações causais entre as variáveis latentes formadas pelos construtos analisados (Hair Jr., Hult, Ringle \& Sarstedt, 2017).

Para Hair Jr. et al. (2017), um modelo de caminho PLS-SEM compõe-se de duas etapas: i) o modelo de mensuração, utilizado para garantir a validade entre os construtos definidos e seus itens, por meio dos testes de validade convergente (usada para explicar as correlações entre os itens de um mesmo construto, mediante as métricas das cargas fatoriais externas, confiabilidade dos indicadores; e average variance extracted), confiabilidade da consistência interna (usada para julgar a consistência dos resultados entre os itens no mesmo construto, a partir da confiabilidade composta e alfa de Cronbach) e validade discriminante (usada para avaliar a extensão em que um construto é empiricamente distinto dos demais no modelo estrutural, com base no heterotraitmonotrait); e ii) o modelo de estruturação, utilizado para avaliar as relações entre as variáveis latentes apresentadas, por intermédio dos testes de hipóteses estabelecidos no estudo.

\section{ANÁLISE DOS RESULTADOS}

\subsection{Perfil dos Respondentes e Análise Descritiva}

Na Tabela 1, evidencia-se o perfil dos respondentes da pesquisa, com destaque ao gênero, faixa etária, fase do curso, se trabalha e se trabalha na área contábil.

\section{Tabela 1}

Perfil dos respondentes

\begin{tabular}{|c|c|c|c|c|c|}
\hline Gênero & Frequência & $\%$ & Faixa Etária & Frequência & $\%$ \\
\hline Masculino & 87 & 39 & entre 15 e 20 anos & 54 & 24 \\
\hline \multirow[t]{4}{*}{ Feminino } & 138 & 61 & entre 21 e 25 anos & 100 & 44 \\
\hline & & & entre 26 e 30 anos & 48 & 21 \\
\hline & & & entre 31 e 35 anos & 14 & 6 \\
\hline & & & acima de 35 anos & 9 & 4 \\
\hline Fase do Curso & Frequência & $\%$ & Trabalha & Frequência & $\%$ \\
\hline $2^{\circ}$ ano $/ 3^{\circ}$ semestre & 16 & 7 & Sim & 208 & 92 \\
\hline $2^{\circ}$ ano $/ 4^{\circ}$ semestre & 12 & 5 & Não & 17 & 8 \\
\hline $3^{\circ}$ ano $/ 5^{\circ}$ semestre & 36 & 16 & INUO & & 0 \\
\hline $3^{\circ}$ ano $/ 6^{\circ}$ semestre & 60 & 27 & Trabalha na Área Contábil & Frequência & $\%$ \\
\hline $4^{\circ}$ ano $/ 7^{\circ}$ semestre & 69 & 31 & Sim & 115 & 55 \\
\hline $4^{\circ}$ ano $/ 8^{\circ}$ semestre & 32 & 14 & Não & 93 & 45 \\
\hline
\end{tabular}

Fonte: Dados da pesquisa. 
Os dados demográficos identificados na pesquisa, de acordo com a Tabela 2, demonstram que $61 \%$ dos acadêmicos são do gênero feminino. A faixa etária que mais se destacou (44\%) foi dos acadêmicos entre 21 e 25 anos. Em relação a fase do curso, $31 \%$ dos respondentes estão no $4^{\circ}$ ano $/ 7^{\circ}$ semestre, seguido com $27 \%$ dos respondentes do $3^{\circ}$ ano $/ 6^{\circ}$ semestre do curso de graduação em Ciências Contábeis. Com relação ao trabalho, verifica-se que 92\% dos acadêmicos possuem atividade remunerada. Além disso, que $55 \%$ desempenham a função ou cargo na área contábil. Os resultados demográficos apresentados sugerem que os acadêmicos reúnem as condições necessárias para responder o instrumento de pesquisa, em especial considerando-se a quantidade de estudantes que trabalham, o que pode afetar as atividades acadêmicas. Na Tabela 2, apresenta-se os resultados da estatística descritiva dos construtos analisados na pesquisa.

\section{Tabela 2}

Estatística descritiva

\begin{tabular}{|c|c|c|c|c|c|c|c|c|}
\hline $\begin{array}{l}\text { Variável } \\
\text { Latente }\end{array}$ & Indicadores & Mínimo & Máximo & Média & $\begin{array}{l}\text { Desvio- } \\
\text { Padrão }\end{array}$ & $\begin{array}{c}\text { Coeficiente } \\
\text { de } \\
\text { Variação }\end{array}$ & Assimetria & Curtose \\
\hline \multirow{13}{*}{$\begin{array}{l}\text { Antece- } \\
\text { dentes } \\
\text { Pessoais }\end{array}$} & $\mathrm{APl}$ & 1 & 6 & 2,911 & 1,467 & $50,401 \%$ & 0,215 & $-0,905$ \\
\hline & AP2 & 1 & 6 & 3,236 & 1,545 & $47,743 \%$ & 0,032 & $-1,111$ \\
\hline & AP3 & 1 & 6 & 2,053 & 1,345 & $65,514 \%$ & 1,368 & 1,196 \\
\hline & AP4 & 1 & 6 & 1,933 & 1,134 & $58,650 \%$ & 1,392 & 1,735 \\
\hline & AP5 & 1 & 6 & 3,400 & 1,642 & $48,296 \%$ & 0,060 & $-1,158$ \\
\hline & AP6 & 1 & 6 & 2,231 & 1,306 & $58,530 \%$ & 0,996 & 0,378 \\
\hline & AP7 & 1 & 6 & 3,676 & 1,863 & $50,682 \%$ & $-0,166$ & $-1,456$ \\
\hline & AP8 & 1 & 6 & 3,369 & 1,942 & $57,631 \%$ & 0,041 & $-1,601$ \\
\hline & AP9 & 1 & 6 & 2,964 & 1,658 & $55,927 \%$ & 0,419 & $-1,067$ \\
\hline & AP10 & 1 & 6 & 2,880 & 1,572 & $54,594 \%$ & 0,402 & $-0,976$ \\
\hline & AP11 & 1 & 6 & 2,147 & 1,279 & $59,559 \%$ & 1,003 & 0,403 \\
\hline & AP12 & 1 & 6 & 2,604 & 1,392 & $53,432 \%$ & 0,554 & $-0,569$ \\
\hline & AP13 & 1 & 6 & 2,484 & 1,347 & $54,202 \%$ & 0,625 & $-0,199$ \\
\hline \multirow{12}{*}{$\begin{array}{c}\text { Antece } \\
\text { dentes } \\
\text { Situacio } \\
\text { nais }\end{array}$} & ASI & 1 & 6 & 3,338 & 1,553 & $46,532 \%$ & 0,101 & $-0,935$ \\
\hline & AS2 & 1 & 6 & 2,507 & 1,261 & $50,310 \%$ & 0,699 & 0,113 \\
\hline & AS3 & 1 & 6 & 2,364 & 1,518 & $64,198 \%$ & 0,895 & $-0,278$ \\
\hline & AS4 & 1 & 6 & 3,676 & 1,657 & $45,092 \%$ & $-0,048$ & $\begin{array}{l}-1,229 \\
\end{array}$ \\
\hline & AS5 & 1 & 6 & 3,756 & 1,752 & $46,650 \%$ & $-0,244$ & $-1,265$ \\
\hline & AS6 & 1 & 6 & 3,516 & 1,607 & $45,700 \%$ & 0,092 & $-1,047$ \\
\hline & AS7 & 1 & 6 & 3,000 & 1,491 & $49,701 \%$ & 0,383 & $-0,875$ \\
\hline & AS8 & 1 & 6 & 3,916 & 1,385 & $35,360 \%$ & $-0,377$ & $-0,613$ \\
\hline & AS9 & 1 & 6 & 3,800 & 1,742 & $45,851 \%$ & $-0,282$ & $-1,335$ \\
\hline & AS 10 & 1 & 6 & 3,671 & 1,658 & $45,160 \%$ & $-0,093$ & $-1,282$ \\
\hline & AS11 & 1 & 6 & 3,676 & 1,764 & $48,003 \%$ & $-0,112$ & $-1,341$ \\
\hline & AS12 & 1 & 6 & 1,987 & 1,262 & $63,542 \%$ & 1,248 & 0,842 \\
\hline \multirow{10}{*}{$\begin{array}{c}\text { Procrasti } \\
\text { nação } \\
\text { Acadê } \\
\text { mica }\end{array}$} & PAl & 1 & 6 & 3,231 & 1,677 & $51,902 \%$ & 0,174 & $-1,193$ \\
\hline & PA2 & 1 & 6 & 2,978 & 1,501 & $50,418 \%$ & 0,366 & $-0,885$ \\
\hline & PA3 & 1 & 6 & 4,000 & 1,724 & $43,108 \%$ & $-0,453$ & $-1,064$ \\
\hline & PA4 & 1 & 6 & 3,809 & 1,743 & $45,770 \%$ & $-0,224$ & $-1,205$ \\
\hline & PA5 & 1 & 6 & 3,591 & 1,492 & $41,536 \%$ & $-0,162$ & $-0,826$ \\
\hline & PA6 & 1 & 6 & 3,476 & 1,727 & $49,691 \%$ & 0,089 & $-1,338$ \\
\hline & PA7 & 1 & 6 & 3,342 & 1,769 & $52,916 \%$ & 0,149 & $-1,368$ \\
\hline & PA8 & 1 & 6 & 3,653 & 1,710 & $46,805 \%$ & $-0,016$ & $-1,353$ \\
\hline & PA9 & 1 & 6 & 2,498 & 1,430 & $57,263 \%$ & 0,674 & $-0,447$ \\
\hline & PA10 & 1 & 6 & 3,956 & 1,490 & $37,678 \%$ & $-0,789$ & $-0,292$ \\
\hline
\end{tabular}




\begin{tabular}{|c|c|c|c|c|c|c|c|c|}
\hline & Indicadores & Mínimo & Máximo & Média & $\begin{array}{l}\text { Desvio- } \\
\text { Padrão }\end{array}$ & $\begin{array}{c}\text { Coeficiente } \\
\text { de } \\
\text { Variação }\end{array}$ & Assimetria & Curtose \\
\hline & PAll & 1 & 6 & 4,747 & 1,449 & $30,535 \%$ & $-1,165$ & 0,659 \\
\hline & PA12 & 1 & 6 & 3,200 & 1,706 & $53,315 \%$ & 0,403 & $-1,038$ \\
\hline \multirow{11}{*}{$\begin{array}{l}\text { Desvio } \\
\text { de } \\
\text { Condut } \\
\text { a }\end{array}$} & $\mathrm{DCl}$ & 1 & 5 & 1,138 & 0,636 & $55,936 \%$ & 5,328 & 28,838 \\
\hline & DC2 & 1 & 5 & 1,422 & 0,913 & $64,224 \%$ & 2,502 & 5,898 \\
\hline & DC3 & 1 & 6 & 1,613 & 1,088 & $67,464 \%$ & 1,907 & 3,037 \\
\hline & $\mathrm{DC4}$ & 1 & 5 & 1,542 & 0,968 & $62,760 \%$ & 1,653 & 1,623 \\
\hline & DC5 & 1 & 6 & 1,556 & 1,113 & $71,559 \%$ & 2,396 & 5,540 \\
\hline & DC6 & 1 & 6 & 1,964 & 1,089 & $55,443 \%$ & 1,075 & 1,169 \\
\hline & DC7 & 1 & 6 & 1,236 & 0,809 & $65,457 \%$ & 3,785 & 14,609 \\
\hline & DC8 & 1 & 6 & 2,982 & 1,476 & $49,490 \%$ & 0,384 & $-0,580$ \\
\hline & DC9 & 1 & 6 & 2,320 & 1,241 & $53,490 \%$ & 0,942 & 0,421 \\
\hline & DC10 & 1 & 5 & 1,738 & 1,017 & $58,504 \%$ & 1,162 & 0,165 \\
\hline & DC11 & 1 & 6 & 2,693 & 1,703 & $63,240 \%$ & 0,745 & $-0,754$ \\
\hline \multirow{2}{*}{$\begin{array}{c}\text { Desemp } \\
\text { enho } \\
\text { Acadê } \\
\text { mico }\end{array}$} & DAl & 1 & 6 & 3,596 & 1,440 & $40,037 \%$ & 0,020 & $-0,708$ \\
\hline & DA2 & 1 & 6 & 3,436 & 1,517 & $44,148 \%$ & 0,186 & $-0,867$ \\
\hline
\end{tabular}

Nota: $\mathrm{AP}=$ Antecedentes Pessoais; $\mathrm{AS}=$ Antecedentes Situacionais; $\mathrm{PA}=$ Procrastinação Acadêmica; $\mathrm{DC}=$ Desvio de Conduta; e DA=Desempenho Acadêmico.

Fonte: Dados da pesquisa.

De modo geral, as respostas foram heterogêneas para os construtos, com médias abaixo do médio da escala, o que pode indicar que os discentes do curso de Ciências Contábeis não possuem características diferentes em relação as assertivas. Como o instrumento foi aplicado com alunos de diferentes fases do curso e faixas etárias, as respostas podem ser divergentes. Além disso, existem valores de assimetria e curtose que extrapolaram o intervalo desejável de -1 e +1 (Hair Jr. et al., 2017). Entretanto, esse quesito não é um pressuposto para o modelo PLS-SEM, pois não requer que os dados possuam distribuição normal (Hair Jr. et al., 2017), assim, nenhuma variável foi excluída neste momento da análise.

\subsection{Modelo de Mensuração}

O modelo de mensuração é realizado para avaliar a adequação do modelo a partir de alguns testes, são eles: i) validade convergente; ii) confiabilidade da consistência interna; e iii) validade discriminante (Hair Jr. et al., 2017). O resumo dos resultados do modelo de mensuração é apresentado na Tabela 3. 
Determinantes e Consequentes da Procrastinação de Discentes em Disciplinas do Curso de Ciências Contábeis

Tabela 3

Resumo dos resultados do modelo de mensuração

\begin{tabular}{|c|c|c|c|c|c|c|c|}
\hline \multirow{2}{*}{$\begin{array}{l}\text { Variável } \\
\text { Latente }\end{array}$} & \multirow{2}{*}{ Indicadores } & \multicolumn{3}{|c|}{ Validade Convergente } & \multicolumn{2}{|c|}{$\begin{array}{l}\text { Confiabilidade da } \\
\text { Consistência Interna }\end{array}$} & \multirow{2}{*}{$\begin{array}{c}\begin{array}{c}\text { Validad } \\
\text { e } \\
\text { Discrimi } \\
\text { nante }\end{array} \\
\text { HTMT } \\
\text { não } \\
\text { inclui } \\
\text { valor } 1\end{array}$} \\
\hline & & $\begin{array}{l}\text { Cargas } \\
\text { Fatoriais } \\
\text { Externas }\end{array}$ & $\begin{array}{l}\text { Confiabilida } \\
\text { de dos } \\
\text { Indicadores }\end{array}$ & AVE & $\begin{array}{l}\text { Confiabilid } \\
\text { ade } \\
\text { Composta }\end{array}$ & $\begin{array}{l}\text { Alfa de } \\
\text { Cronbach }\end{array}$ & \\
\hline \multirow{3}{*}{ AP } & AP4 & 0,776 & 0,603 & \multirow{3}{*}{0,626} & \multirow{3}{*}{0,834} & \multirow{3}{*}{0,705} & \multirow{3}{*}{ Sim } \\
\hline & AP5 & 0,819 & 0,670 & & & & \\
\hline & AP6 & 0,778 & 0,605 & & & & \\
\hline \multirow{5}{*}{ AS } & AS4 & 0,735 & 0,540 & \multirow{5}{*}{0,523} & \multirow{5}{*}{0,845} & \multirow{5}{*}{0,779} & \multirow{5}{*}{ Sim } \\
\hline & AS5 & 0,749 & 0,561 & & & & \\
\hline & AS9 & 0,707 & 0,501 & & & & \\
\hline & AS10 & 0,740 & 0,548 & & & & \\
\hline & AS11 & 0,681 & 0,464 & & & & \\
\hline \multirow{7}{*}{ PA } & PA3 & 0,696 & 0,484 & \multirow{7}{*}{0,507} & \multirow{7}{*}{0,875} & \multirow{7}{*}{0,830} & \multirow{7}{*}{ Sim } \\
\hline & PA4 & 0,670 & 0,448 & & & & \\
\hline & PA5 & 0,442 & 0,195 & & & & \\
\hline & PA6 & 0,715 & 0,511 & & & & \\
\hline & PA7 & 0,838 & 0,703 & & & & \\
\hline & PA8 & 0,798 & 0,636 & & & & \\
\hline & PA12 & 0,755 & 0,569 & & & & \\
\hline \multirow{4}{*}{ DC } & DC6 & 0,670 & 0,448 & \multirow{4}{*}{0,527} & \multirow{4}{*}{0,816} & \multirow{4}{*}{0,713} & \multirow{4}{*}{ Sim } \\
\hline & $\mathrm{DC} 8$ & 0,660 & 0,436 & & & & \\
\hline & DC9 & 0,757 & 0,573 & & & & \\
\hline & DC11 & 0,807 & 0,652 & & & & \\
\hline \multirow{2}{*}{ DA } & DAl & 0,907 & 0,823 & \multirow{2}{*}{0,841} & \multirow{2}{*}{0,913} & \multirow{2}{*}{0,811} & \multirow{2}{*}{ Sim } \\
\hline & DA2 & 0,927 & 0,859 & & & & \\
\hline
\end{tabular}

Nota: AP=Antecedentes Pessoais; AS=Antecedentes Situacionais; PA=Procrastinação Acadêmica; $\mathrm{DC}=$ Desvio de Conduta; $\mathrm{DA}=$ Desempenho Acadêmico; $\mathrm{AVE}=$ Average Variance Extracted; e HTMT=Heterotrait-Monotrait. Valores recomendados para: i) cargas fatoriais externas $\geq 0,7$; ii) $\mathrm{AVE} \geq 0,5$; iii) confiabilidade composta $\geq 0,7$; iv) alfa de Cronbach $\geq 0,7$; v) intervalo de confiança HTMT < 1 (Hair Jr. et al., 2017).

Fonte: Dados da pesquisa.

O primeiro teste aplicado para validação do modelo teórico, recomendado por Hair Jr. et al. (2017) é a validade convergente, por meio dos valores das cargas fatoriais externas, em que as assertivas devem apresentar cargas fatoriais acima de 0,7, para demonstrar adequação do modelo utilizado, porém, as assertivas que apresentarem cargas fatoriais entre 0,4 e 0,7 só devem ser removidas quando a sua exclusão levar a um aumento da validade convergente e na confiabilidade composta acima do valor recomendável. Das 13 assertivas do construto antecedentes pessoais, somente 3 apresentaram carga fatorial apropriada. Quanto aos antecedentes situacionais, apenas 5 assertivas permaneceram no construto. Para a procrastinação acadêmica, 7 se demonstraram adequadas. Finalmente, 4 assertivas do desvio de conduta exibiram valores satisfatórios. A validade convergente também foi validada pela variância média extraída (AVE), pois cada variável latente apresentou medida superior ao limite aceitável de 0,5 (Hair Jr. et al., 2017).

Para confiabilidade da consistência interna, foi realizado a análise da 
confiabilidade composta e o alfa de Cronbach, em que os valores de cada construto devem ser maiores que 0,6 (Hair Jr. et al., 2017). A Tabela 4 mostra que a confiabilidade composta e o alfa de Cronbach de todas as variáveis latentes, atingiram os valores mínimos necessários, logo, os itens utilizados para representar os construtos apresentam confiabilidade de consistência interna satisfatória. Por fim, observou-se que em todas as variáveis latentes, o intervalo de confiança HTMT não inclui valor 1, portanto, elas são explicitamente independentes uma das outras, isso indica que a validade discriminante foi estabelecida (Hair Jr. et al., 2017).

\subsection{Modelo de Estruturação}

Após a verificação dos testes para o modelo de mensuração, o próximo passo é realizar a análise do modelo de estruturação, com a finalidade de testar a força e a direção das relações entre as variáveis latentes utilizadas no estudo (Hair Jr. et al., 2017). Na Tabela 4, apresenta-se a colinearidade (VIF), coeficiente de determinação $\left(R^{2}\right)$, as relações do modelo estrutural (teste de hipóteses) e o tamanho do efeito $\left(f^{2}\right)$.

\section{Tabela 4}

Resumo dos resultados do modelo de mensuração

\begin{tabular}{c|c|c|c|c|c|c|c|c|c}
\hline $\begin{array}{c}\text { Relação } \\
\text { Estrutural }\end{array}$ & $\begin{array}{c}\text { Coeficiente } \\
\text { Estrutural }\end{array}$ & $\begin{array}{c}\text { Erro- } \\
\text { Padrão }\end{array}$ & $\begin{array}{c}\text { Valor- } \\
\boldsymbol{t}\end{array}$ & $\begin{array}{c}\text { Valor- } \\
\boldsymbol{p}\end{array}$ & VIF & $\boldsymbol{R}^{2}$ & $\boldsymbol{f}$ & \multicolumn{2}{|c}{ Hipóteses } \\
\hline $\mathrm{AP} \rightarrow \mathrm{PC}$ & 0,388 & 0,051 & 7,592 & $0,000^{*}$ & 1,340 & \multirow{2}{*}{0,522} & 0,236 & $\mathrm{H}_{1}$ & $\begin{array}{c}\text { Não } \\
\text { Rejeita-se }\end{array}$ \\
\hline $\mathrm{AS} \rightarrow \mathrm{PC}$ & 0,444 & 0,055 & 8,050 & $0,000^{*}$ & 1,340 & 0,308 & $\mathrm{H}_{1}$ & $\begin{array}{c}\text { Não } \\
\text { Rejeita-se }\end{array}$ \\
\hline $\mathrm{PC} \rightarrow \mathrm{DC}$ & 0,591 & 0,036 & 16,336 & $0,000^{*}$ & 1,000 & 0,349 & 0,536 & $\mathrm{H}_{2}$ & $\begin{array}{c}\text { Não } \\
\text { Rejeita-se }\end{array}$ \\
\hline $\mathrm{PC} \rightarrow \mathrm{DA}$ & $-0,116$ & 0,069 & 1,685 & $0,093^{* *}$ & 1,000 & 0,014 & 0,014 & $\mathrm{H}_{3}$ & $\begin{array}{c}\text { Não } \\
\text { Rejeita-se }\end{array}$ \\
\hline
\end{tabular}

Nota: AP=Antecedentes Pessoais; AS=Antecedentes Situacionais; PA=Procrastinação Acadêmica; DC=Desvio de Conduta; DA=Desempenho Acadêmico; e VIF=Variance Inflation Factor. Valores recomendados para: i) Tamanho do efeito $f^{2}: \geq 0,02$ pequeno, $\geq 0,15$ médio e $\geq 0,35$ grande; i) Variância explicada $R^{2}: \geq 0,25$ fraco, $\geq 0,5$ moderado e $\geq 0,75$ substancial; e iii) VIF < 5 (Hair Jr. et al., 2017). *significância ao nível de 1\%; e **significância ao nível de 10\%.

Fonte: Dados da pesquisa.

A Tabela 4 apresenta evidências de não haver problemas de multicolinariedade entre os construtos exógenos, pois os resultados foram maiores que 0,2 , mas menores que 5, portanto, não existe a necessidade da retirada de nenhuma variável independente. Observa-se que os antecedentes pessoais e situacionais explicam a procrastinação acadêmica em $52,2 \%\left(R^{2}\right)$, em que os antecedentes situacionais são os maiores preditores. Já a procrastinação acadêmica explica em 34,9\% $\left(R^{2}\right)$ o desvio de conduta e $1,14 \%\left(R^{2}\right)$ o desempenho acadêmico. Constata-se um valor muito baixo de explicação para o desempenho acadêmico. Entretanto, não foi possível comparar os resultados do $R^{2}$ com pesquisas anteriores, pois nem todos utilizaram a modelagem de equações estruturais e aqueles que a aplicaram não apresentaram os respectivos coeficientes de determinação. Assim, considera-se válidos os valores dos $R^{2}$ deste estudo. 
Como apresentado na Tabela 5, a $\mathrm{H}_{1}$ não é rejeitada, ou seja, a procrastinação acadêmica é afetada de forma positiva pelos antecedentes pessoais (médio efeito, $f^{2}=0,236$; $\beta=0,388$; valor $t=7,592$; valor- $p<0,01$ ) e pelos antecedentes situacionais (grande efeito, $f^{2}=0,308 ; \beta=0,444$; valor- $t=8,050$; valor$p<0,01)$. O estudo também prevê que a procrastinação acadêmica possui relação positiva e significativa com o desvio de conduta e negativa com o desempenho acadêmico. Especificamente, os estudantes ao terem comportamento procrastinador apresentam maior desvio de conduta (grande efeito, $f^{2}=0,536 ; \beta=0,591$; valor- $t=16,336$; valor- $p<0,01$ ), assim não rejeita-se a $\mathrm{H}_{2}$. Por fim, os discentes procrastinadores também apresentam um baixo desempenho acadêmico (baixo efeito, $f^{2}=0,014 ; \beta=-0,116$; valor $t=1,685$; valor $-p<0,10$ ), logo, $a$ $\mathrm{H}_{3}$ não é rejeitada.

\subsection{Discussão dos Resultados}

Na Figura 3, apresenta-se o modelo teórico com os resultados estimados pela modelagem PLS-SEM.

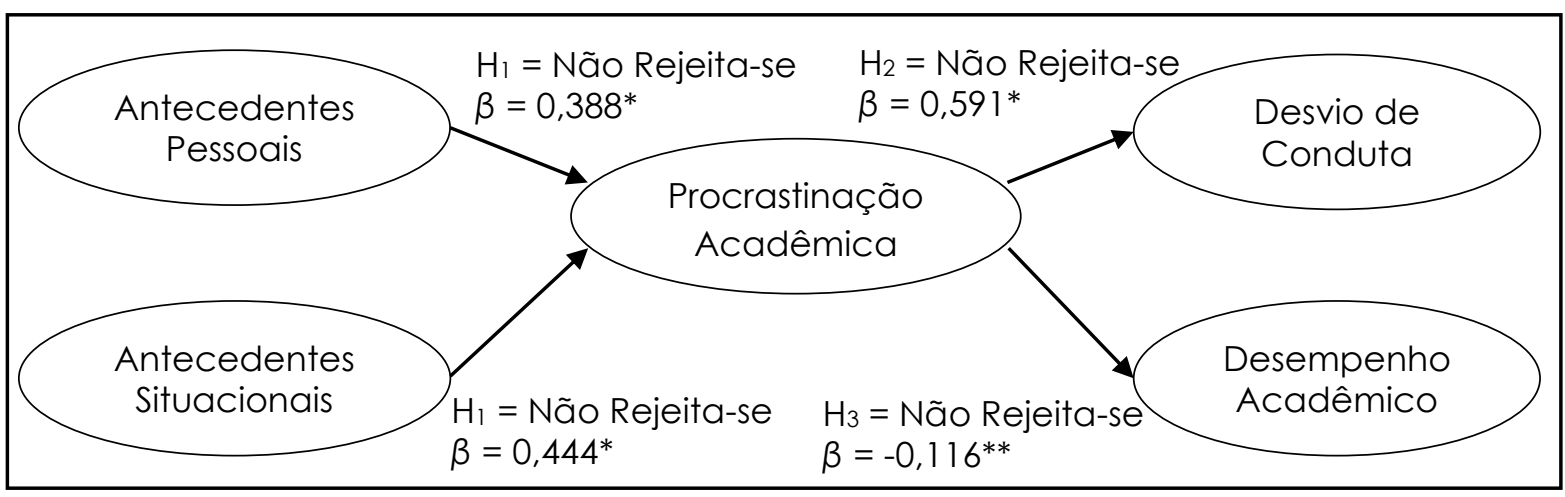

Figura 3 - Resultados do modelo relacional da pesquisa

Nota: *significância ao nível de 1\%; e **significância ao nível de $10 \%$.

Fonte: Dados da pesquisa.

A hipótese $\mathrm{H}_{1}$ prevê que há relação significativa entre os motivos pessoais e situacionais e a procrastinação, e pelos resultados aceita-se a $\mathrm{H}_{1}$. Assim, os discentes que não conseguem iniciar as atividades, mesmo possuindo vontade, que possuem facilidade para distração e não conseguem cumprir as tarefas no prazo, são considerados procrastinadores. Além disso, alunos com compromissos fora da universidade, se distraem com maior frequência, isso ocorre por não considerarem as tarefas acadêmicas atraentes ou importantes comparado aos demais compromissos, além de não terem incentivos para a realização das mesmas, apresentando assim um comportamento procrastinador. Esses resultados corroboram com os de Milgram et al. (1992), que analisaram motivos pessoais e situacionais, de Ferrari e Scher (2000), que analisaram motivos situacionais, e de Dewitte e Schouwenburg (2002), que analisaram motivos pessoais, como antecedentes da procrastinação acadêmica.

Milgram et al. (1992) afirmam que o autocontrole está positivamente correlacionado com a procrastinação, e que aqueles discentes que receberam explicação plausível sobre a finalidade da pesquisa tiveram um baixo nível de 
procrastinação. Já Ferrari e Scher (2000) afirmam que quanto mais desagradável for a tarefa, independentemente de ser acadêmica ou não, maior será a procrastinação. Finalmente, Dewitte e Schouwenburg (2002) identificaram que os discentes que não conseguem ter um autocontrole para não cair em tentação com qualquer tipo de distração, irão procrastinar as atividades acadêmicas.

A hipótese $\mathrm{H}_{2}$ postula que há relação positiva entre a procrastinação e o desvio de conduta acadêmica. Os resultados sugerem que o comportamento procrastinador por parte dos discentes leva os mesmos a terem desvios de conduta acadêmica. Assim, aceita-se a $\mathrm{H}_{2}$ do estudo, o que coaduna com a pesquisa de Patrzek et al. (2014), em que foi aplicado um questionário entre 1.359 e 2.207 discentes de diferentes disciplinas acadêmicas em quatro universidades alemãs, e foi identificado que a procrastinação acadêmica influencia no desvio de conduta. Nota-se que os discentes procrastinadores apresentaram maior desvio de conduta, tais como, copiar parte do dever de casa dos colegas, más condutas acadêmicas (navegação nas redes sociais e conversas paralelas com os colegas durante as aulas) e a não realização de leituras do material proposto pelo professor para o acompanhamento do conteúdo da aula seguinte (Patrzek et al., 2014).

A hipótese $\mathrm{H}_{3}$ prevê que há relação negativa entre a procrastinação e o desempenho acadêmico. Os resultados evidenciam, ao nível de significância de $10 \%$, que a procrastinação acadêmica está negativamente relacionada com o desempenho acadêmico, com um coeficiente de caminho de 0,116. Assim, pode-se afirmar que discentes procrastinadores são mais propensos a apresentar um desempenho acadêmico menor, por não terem dedicação satisfatória às disciplinas da área contábil, em comparação aos demais colegas que apresentam bom desempenho acadêmico. Reforça ainda a importância dos alunos do curso de Ciências Contábeis tentar diminuir o comportamento procrastinador, a fim de não prejudicar a vida acadêmica no curso. Os achados suportam a $\mathrm{H}_{3}$, o que apoia os estudos de Ribeiro et al. (2014), Kim e Seo (2015), Amaro et al. (2016), Grunschel et al. (2016), Silva et al. (2016) e Semprebon et al. (2017).

Kim e Seo (2015), ao realizarem uma meta-análise de 33 estudos, identificaram que o ato de procrastinar as tarefas universitárias impacta de forma positiva no desempenho acadêmico. Na pesquisa realizada por Ribeiro et al. (2014) foi observado que o comportamento procrastinador afetou o desempenho acadêmico de alunos dos cursos de graduação em Ciências Contábeis nas três instituições públicas de ensino superior brasileiras investigadas. Verificaram que esse comportamento não possui diferenças relacionadas ao gênero. Para Ribeiro et al. (2014, p. 403), "[...] a profissão contábil envolve usualmente o cumprimento de prazos para o fornecimento de relatórios e análises, quer sejam internos às organizações, quer sejam externos". Dessa forma, a procrastinação possui um impacto relevante para o profissional da área contábil.

Grunschel et al. (2016) identificaram que os discentes que utilizam as estratégias de regulação motivacional para diminuir o ato de procrastinar apresentam melhor desempenho e são mais satisfeitos com a vida acadêmica e pessoal. Silva et al. (2016) identificaram que os discentes do curso de Ciências Contábeis que responderam ter comportamento procrastinador apresentam rendimento acadêmico de baixo a médio, ao passo que aqueles cujo 154 Revista Contabilidade Vista \& Revista, ISSN 0103-734X, Universidade Federal de Minas Gerais, Belo Horizonte, v. 31, n. 1, p. 136-158, jan./abr. 2020 
comportamento foi classificado como não procrastinador possuem rendimento acadêmico de médio a alto. Os autores ressaltam uma grande preocupação com $\circ$ fato de os respondentes afirmarem que possuem comportamento procrastinador, pois a universidade busca preparar os discentes para a vida profissional, em que os contadores devem observar e cumprir prazos e limites de tempo diariamente dentro e fora das organizações.

Amaro et al. (2016) averiguaram que a procrastinação exerce influência negativa na autoavaliação de desempenho quando os discentes possuem baixa autoeficácia, em se tratando de alunos da área de Ciências Sociais Aplicadas. Semprebon et al. (2017) verificaram que a procrastinação acadêmica influencia negativamente no desempenho dos discentes dos cursos de Ciências Contábeis, Ciências Econômicas, Administração, Marketing e Turismo, mas que esta relação só pode ser confirmada nos estudantes com baixo censo de poder.

\section{CONCLUSÃO}

O estudo investigou fatores que levam à procrastinação de discentes do curso de Ciências Contábeis em disciplinas da área. Os resultados da pesquisa sinalizam que os antecedentes pessoais e situacionais levam os discentes a procrastinarem as tarefas de disciplinas da área contábil, confirmando-se a hipótese $\mathrm{H}_{1}$ e coadunando-se com as pesquisas de Milgram et al. (1992), Ferrari e Scher (2000), Dewitte e Schouwenburg (2002) e Klingsieck et al. (2013). Assim, os discentes que buscam diminuir o comportamento procrastinador, devem querer realizar as tarefas do curso no prazo estipulado, além de diminuir as distrações do cotidiano que interferem nas atividades acadêmicas. Devem ainda não cair em tentação para distrações do cotidiano, como compromissos e impulsos socais. Já os docentes podem no início das disciplinas propor atividades menos complexas, para maximizar a motivação e programação dos discentes, o que pode auxiliar na redução do comportamento procrastinador e, posteriormente, evoluir com a complexidade das tarefas.

Os resultados da pesquisa fornecem suporte para as proposições de Patrzek et al. (2014), quanto à influência do comportamento procrastinador na geração de desvio de conduta acadêmica dos discentes, confirmando-se a hipótese $\mathrm{H}_{2}$. $\mathrm{O}$ desvio de conduta pode afetar a integridade acadêmica e profissional do discente, pois ao cometer atos de má fé no âmbito universitário, também poderá ter um desvio de conduta na vida profissional, e que este comportamento é apresentado por procrastinadores (Patrzek et al., 2014). Isso é preocupante na área de negócios, visto que várias empresas têm passado por escândalos de corrupção. Assim, toda a comunidade acadêmica deve auxiliar os estudantes a diminuírem o comportamento procrastinador, prevenindo os desvios de conduta.

O estudo também confirmou que o comportamento procrastinador por parte dos discentes afeta o desempenho acadêmico, aceitando-se a hipótese $\mathrm{H}_{3}$, O que corrobora com as pesquisas de Ribeiro et al. (2014), Kim e Seo (2015), Amaro et al. (2016), Grunschel et al. (2016), Silva et al. (2016) e Semprebon et al. (2017). Os resultados da pesquisa indicam que os discentes da amostra são considerados procrastinadores negativos, pois não conseguem planejar o tempo 
para a realização das tarefas acadêmicas dentro do prazo determinado, o que prejudica o desempenho e aumenta o desvio de conduta na vida acadêmica.

Conclui-se com base nos resultados e da amostra pesquisada que os fatores pessoais e situacionais levam à procrastinação de discentes do curso de Ciências Contábeis em disciplinas da área. Destaca-se em específico os antecedentes situacionais, com um maior coeficiente de explicação. Por fim, o comportamento procrastinador pode afetar tanto o desempenho acadêmico como o desvio de conduta dos discentes, colocando em risco as notas das disciplinas e acarretar na perda do curso.

Os resultados do estudo contribuem para que docentes e discentes do curso de Ciências Contábeis reflitam sobre os resultados negativos da procrastinação no decorrer das disciplinas e para a elaboração de planos e estratégias pedagógicas que possam contribuir com a trajetória acadêmica dos alunos. Embora a pesquisa não tenha abordado maneiras específicas que auxiliem na redução do comportamento procrastinador, indica quais são seus antecedentes pessoais e situacionais. Assim, encaminhar os estudantes a intervenções motivacionais e emocionais, ou estabelecer ambientes acadêmicos que aprimoram a autorregulação acadêmica, tais como o gerenciamento de tempo e estabelecimento de metas para o cumprimento das tarefas do curso, podem ser interessantes e eficazes.

Apesar das contribuições do estudo destacadas quanto ao escopo pesquisado, ele está sujeito a limitações. Destaca-se inicialmente como limitação que os dados da pesquisa relatam as percepções dos discentes do curso de Ciências Contábeis, o que não pode ser generalizado para os discentes de outros cursos. Outra limitação é que foi utilizado o auto-relato para o desempenho acadêmico, o que pode não demonstrar o real desempenho dos discentes. Recomenda-se realizar pesquisas experimentais, qualitativas e longitudinais, que possam fornecer evidências empíricas para apoiar as causas do comportamento procrastinador dos discentes e seus possíveis impactos na vida acadêmica. Finalmente, a extensão dos estudos pode incluir alunos de pós-graduação em Ciências Contábeis, tanto do lato sensu como do stricto sensu.

\section{REFERÊNCIAS}

Amaro, H.D., Semprebon, E., Junior, E.A.B., \& Dezevecki, A.F. (2016). Influência da procrastinação acadêmica na autoavaliação de desempenho de acordo com o nível de autoeficácia do discente. Revista Universo Contábil, 12(4), 4867. https://doi.org/10.4270/RUC.2016427

Carpenter, D.D., Harding, T.S., Finelli, C.J., Montgomery, S.M., \& Passow, H.J. (2006). Engineering students' perceptions of and attitudes towards cheating. Journal of Engineering Education, 95(3), 181-194. https://doi.org/10.1002/j.21689830.2006.tb00891.x

Chu, A.H.C., \& Choi, J.N. (2005). Rethinking procrastination: positive effects of" active" procrastination behavior on attitudes and performance. The Journal of Social Psychology, 145(3), 245-264. https://doi.org/10.3200/SOCP.145.3.245264

156 Revista Contabilidade Vista \& Revista, ISSN 0103-734X, Universidade Federal de Minas Gerais, Belo Horizonte, v. 31, n. 1, p. 136-158, jan./abr. 2020 
Costa, M.D.S. (2007). Procrastinação, autorregulação e género (Dissertação de mestrado). Instituto de Educação e Psicologia, Universidade do Minho, Braga, Portugal.

Dewitte, S., \& Schouwenburg, H.C. (2002). Procrastination, temptations, and incentives: The struggle between the present and the future in procrastinators and the punctual. European Journal of Personality, 16(6), 469-489. https://doi.org/10.1002/per.461

Ferrari, J.R., \& Scher, S.J. (2000). Toward an understanding of academic and nonacademic tasks procrastinated by students: The use of daily logs. Psychology in the Schools, 37(4), 359-366. https://doi.org/10.1002/15206807(200007)37:4<367::AID-PITS7>3.0.CO;2-Y

Grunschel, C., Schwinger, M., Steinmayr, R., \& Fries, S. (2016). Effects of using motivational regulation strategies on students' academic procrastination, academic performance, and well-being. Learning and Individual Differences, 49, 162-170. https://doi.org/10.1016/j.lindif.2016.06.008

Hair Jr., J.F., Hult, T.M., Ringle, C.M., \& Sarstedt, M. (2017). A Primer on partial least squares structural equation modeling (PLS-SEM). Los Angeles: Sage.

Kim, K.R., \& Seo, E.H. (2015). The relationship between procrastination and academic performance: A meta-analysis. Personality and Individual Differences, 82, 26-33. https://doi.org/10.1016/j.paid.2015.02.038

Klein, H.A., Levenburg, N.M., McKendall, M., \& Mothersell, W. (2007). Cheating during the college years: How do business school students compare?. Journal of Business Ethics, 72(2), 197-206. https://doi.org/10.1007/s10551-006-9165-7

Klingsieck, K.B., Grund, A., Schmid, S., \& Fries, S. (2013). Why students procrastinate: A qualitative approach. Journal of College Student Development, 54 (4), $397-$ 412. https://doi.org/10.1353/csd.2013.0060

Medeiros, K.E.B., Antonelli, R.A., \& Portulhak, H. (2019). Desempenho acadêmico, procrastinação e o uso de tecnologias de informação e comunicação: uma investigação com estudantes da área de negócios. Revista Gestão Organizacional, 12(1), 92-114. https://doi.org/10.22277/rgo.v14il.4731

Milgram, N.A., Dangour, W., \& Ravi, A. (1992). Situational and personal determinants of academic procrastination. The Journal of General Psychology, 119(2), 123-133. https://doi.org/10.1080/00221309.1992.9921166

Patrzek, J., Sattler, S., van Veen, F., Grunschel, C., \& Fries, S. (2015). Investigating the effect of academic procrastination on the frequency and variety of academic misconduct: a panel study. Studies in Higher Education, 40(6), 1014 1029. https://doi.org/10.1080/03075079.2013.854765 
Raash, M., \& Silveira-Martins, E. (2016). Analise do posicionamento procrastinador como (falta de) estratégia para o desempenho acadêmico: uma pesquisa com estudantes de gestão. Revista Meta: Avaliação, 8(24), 463-487. https://doi.org/10.22347/2175-2753v8i24.1043

Ribeiro, F., Avelino, B.C., Colauto, R.D., \& Nova, S.P.D.C.C. (2014). Comportamento procrastinador e desempenho acadêmico de estudantes do curso de ciências contábeis. Advances in Scientific and Applied Accounting, 7(3), 386406. https://doi.org/10.14392/ASAA.2014070304

Ringle, C.M., Silva, D., \& Bido, D.D.S. (2014). Modelagem de equações estruturais com utilização do SmartPLS. Revista Brasileira de Marketing, 13(2), 56-73. https://doi.org/10.5585/remark.v13i2.2717

Semprebon, E., Amaro, H.D., \& Beuren, I.M. (2017). A influência da procrastinação no desempenho acadêmico e o papel moderador do senso de poder pessoal. Archivos Analíticos de Políticas Educativas, 25(25), 1-24. https://doi.org/10.14507/epaa.25.2545

Silva, D.J.M., Silva, M.A., Vilela, M.S.S., \& Oliveira, R.M. (2016). Procrastinação e desempenho acadêmico: indícios por meio da análise de correspondência. Revista Mineira de Contabilidade, 17(3), 16-31.

Simkin, M.G., \& McLeod, A. (2010). Why do college students cheat?. Journal of Business Ethics, 94 (3), 441-453. https://doi.org/10.1007/s10551-009-0275-x

Steel, P., \& Klingsieck, K.B. (2016). Academic procrastination: psychological antecedents revisited. Australian Psychologist, 51(1), 36-46. https://doi.org/10.1111/ap.12173

Agradecimentos:

Os autores agradecem as contribuições de Maria Aparecida Cardozo na construção do instrumento de pesquisa e na coleta de dados da pesquisa. Também agradecem a contribuição de Adriano Dinomar Barp na coleta de dados da pesquisa. 